\title{
LITERATURE RECEIVED \\ ORACOL, A CHESS PROBLEM SOLVER IN ORCA
}

\author{
by Robert-Jan Elias \\ M.Sc. thesis, 1989 \\ Dept. of Mathematics and Computer Science \\ Free University \\ Amsterdam, The Netherlands
}

We quote the abstract:

"Orca is a high-level programming language for the implementation of distributed applications. Although a number of small distributed problems have been solved successfully in Orca (e.g., TSP, Primes), the question remained how Orca would perform in a more complex environment, like the game of chess. Therefore, we have created a Chess Problem Solver to test the language and developed a parallel alpha-beta algorithm with a reasonable speedup (reduction in search time). Furthermore, we have implemented some chess heuristics and studied their behaviour in our program."

\section{INFORMATION FOR CONTRIBUTORS}

Contributors may be interested to know that the ICCA Journal, as of Vol. 10, No. 1, is a source for the Institute for Scientific Information ${ }^{\circledR}$ (ISI) for inclusion in the CompuMath Citation Index ${ }^{\circledR}\left(\mathrm{CMCI}{ }^{\circledR}\right)$, the Automatic Subject Citation Alert (ASCA $\left.{ }^{\circledR}\right)$ and SCISEARCH ${ }^{\circledR}$, ISI's on-line database. The Journal is also a source for the Information Company R.R. Bowker for inclusion in the International Serials Database which is a source for Ulrich's International Periodicals Directory and the DIALOG on-line service.

Being included in the $\mathrm{CMCI}{ }^{\circledR}$, the ICCA Journal is one of the 400 Journals in mathematics, computer science, statistics, operations research, and related disciplines which is abstracted and/or indexed and/or available as tearsheets; this means that the Journal now is accessible in (on-line) database form.

\section{Submission of material}

Contributions to the Journal are welcomed in any form, although preferably by E-mail or on a MS-DOS formatted 5.25 inch diskette. In case contributors prepare their manuscripts with high-quality wordprocessors, it should be noticed that text-files in VENTURA, TEX or TROFF format are processable directly by the Editors, thereby alleviating their task considerably.

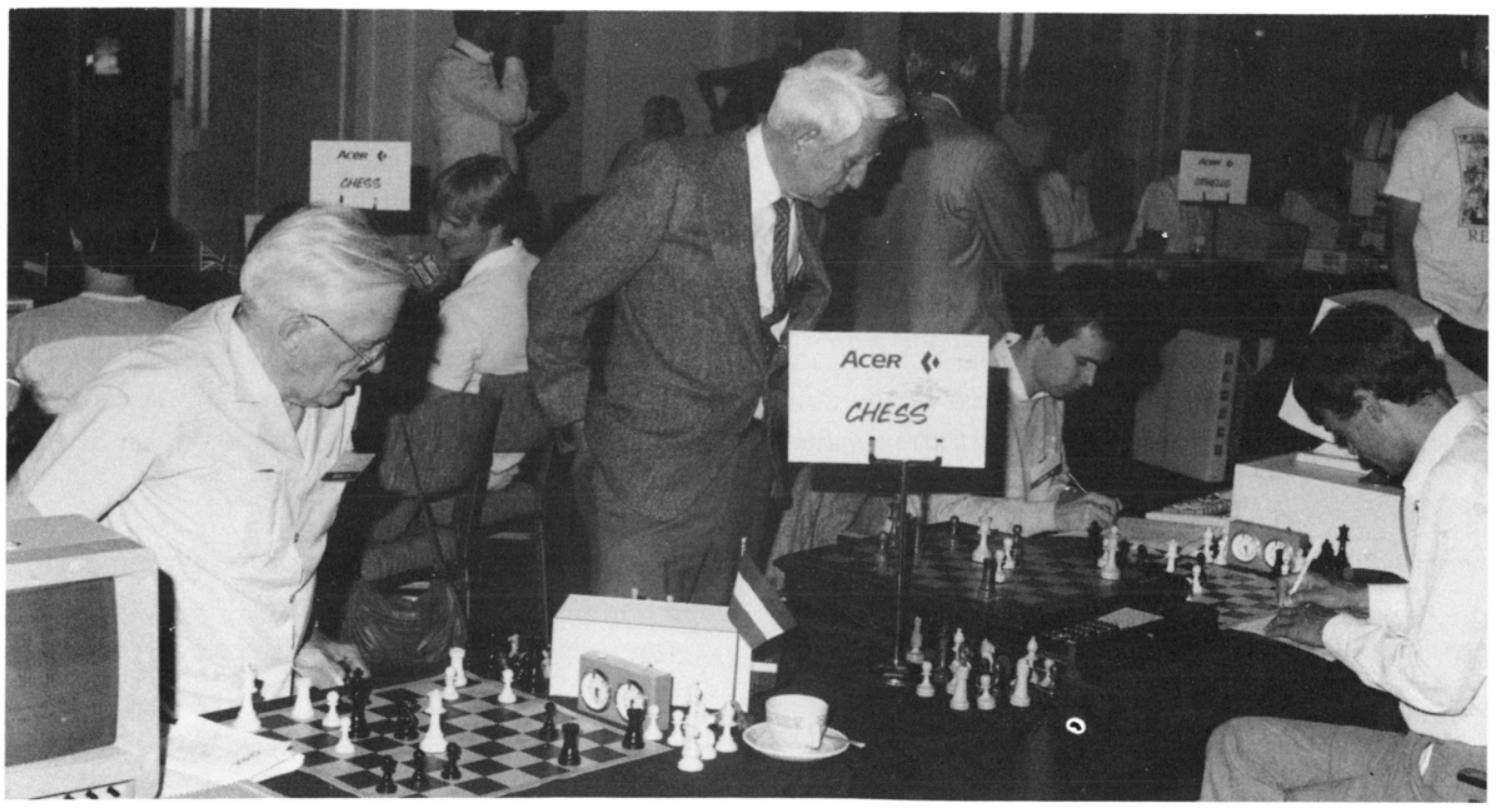

Two honored guests at the first Computer Olympiad: Claude Shannon (centre),

Ken Thompson (right). (London, 1989) 